lergisches Reagieren auf alles Fremde. Wenn Nutting in seiner Darstellung die arabische Nation überbewertet, so bagatellisiert er die enge Verzahnung zwischen Arabismus und Islam; er mißt infolgedessen gegenwärtigen islamischen Ansätzen keine Chance zu (S. 350). Karten, Stammtafeln, Literaturangaben und ein ausführliches Namensregister bilden wertvolle Hilfen zur Erschließung des weitläufigen Themas.

Dr. Conrad Oehlrich, Bonn

\section{David Hirst \\ Oil and Public Opinion in the Middle East}

Faber and Faber, London 1966, 127 S., Sh. 30/-

Angesichts der nicht nur wirtschaftlichen Bedeutung der Ölvorkommen für die arabischen Staaten und deren verständliches Bestreben, von der Ausbeutung dieses Schatzes ihres nationalen Bodens möglichst weitgehend $\mathrm{zu}$ profitieren, wäre es sicher wichtig, die „öffentliche Meinung", wie es im Buchtitel heißt, in Mittelost über die Ölfrage zu erkunden. Ein solches Anliegen begegnet indessen erheblicher Schwierigkeiten, da es, wie Hirst selber feststellt (S. 16), dort keine öffentliche Meinung im westlichen Sinne gibt, da ein Meinungstest schwerlich durchführbar ist, zumal man sich oft scheut, seine Meinung offen zu sagen, und da schließlich die Meinung eines ägyptischen Fellachen, eines jordanischen Beduinen oder eines jordanischen Bergbewohners nicht zählen gegenüber den Meinungen in den Olländern selbst, vor allem also in Irak, Kuwait und Saudien. Auch macht Hirst deutlich, daß in den arabischen Ländern die Politik, auch die OOlpolitik, vielfach diktatorisch ohne Rücksicht auf die allgemeine Meinung gemacht wird, zumal diese Meinung umgekehrt gelenkt wird. Hirst hat sich die Mühe gemacht, sorgfältig die öffentlichen in Reden und Presse bekundeten Meinungen, vor allem auch diejenigen der Jahrestagungen der OPEC (Organization of Petroleum Exporting Countries) zugrunde zu legen. Er hat an der amerikanischen
Universität in Beirut studiert, arbeitet in der libanesischen Hauptstadt am Middle East Research and Publishing Center und schreibt zugleich als Korrespondent für den "Guardian“; er besitzt also eine unbestreitbare Kompetenz für sein Thema.

Was er herausfindet, ist höchst aufschlußreich, wenn es sich auch nicht eigentlich um die öffentliche Meinung handelt, sondern meist um das, was von den Informationsämtern als Meinung lanciert wird; grob gesprochen heißt das: Ölgesellschaften gleich Kolonialismus-Imperialismus (d.h. etwas sehr Schlimmes, ja sogar das Schlimmste), mit dem es eigentlich kein Verhandeln und Paktieren geben darf. Die syrische Baath-Partei brandmarkte daher Nasser, als er sein Jemen-Unternehmen startete, als Handlanger des „US-OOlkapitalismus", wie umgekehrt Nasser sein irakisches Pendent Kassem beschuldigt hatte, im Solde der britischen OOlinteressen zu stehen, als er mit der Iraq Petroleum Company verhandelte. Es ergibt sich mithin ein Bild voller Sentiments und Tabus, in dem man sich nicht zurechtfindet, wenn man nicht die Grundsituation im Auge behält.

Hirst ist teilweise Opfer seines Themas geworden. Er hat es versäumt, die Situation der öffentlichen Meinung im Mittelost zusammenfassend und mit aller Deutlichkeit aufzuzeigen; stattdessen hat er es bei allerdings wiederholten Andeutungen bewenden lassen. Auch wäre es wohl nützlicher gewesen, der Meinung in den verschiedenen Ländern nachzugehen, anstatt die Meinungen zu den politischen, wirtschaftlichen und anderen Aspekten der Ölfrage für Mittelost insgesamt aufzuzeigen. Das auf diese Weise gewonnene Ergebnis ist nicht schlüssig.

Dr. Conrad Oehlrich, Bonn 